\title{
DERECHO PROCESAL CIVIL.
}

\section{La Excepción de Cosa Juzgada}

\author{
Por el Dr. DANIEL OLAECHEÃ ALVAREZ - CALDERON.
}

La Cosa Juzgada junto con la Transacción son las dos excepciones perentorias que nuestro Código de Procedimientos Civiles incluye como dilatorias en el artículo 312 .

El fin de toda controversia judicial es definir las pretensiones dedueidas por las partes en el juicio y el acto judicial que la determina se denomina sentencia. La sentencia se dice que es firme o que está ejecutoriada, cuando contra ella no se puede interponer ningún recurso, ya sea porque el interesado ha hecho uso de todos los medios de impugnación señalados on la ley o porque ha vencido el término que ella franquea para hacer valer los medios de impugnación sin que el interesado los haya ejercitado.

Castro define la Cosa Juzgada diciendo que: "es un efecto de la sentencia, que impide que nuevamente se vuelva a discutir, entre las mismas partes y por la misma causa, lo que ya fué una vez objeto de discusión $Y$ de resolución judicial" (1).

Para Chiovenda (2), la Cosa Juzgada: "no en otra cosa que el bien reconocido o desconocido por el Juez".

El tema de la Cosa Juzgada es sumamente complejo y es necesario considerar en él una serie de aspectos.

\section{Cosa Juzgada y Precluslón.}

Entre la Cosa Juzgada y la Preclusión existe una relación estrecha: de un lado hay evidentes semejanzas, pero, de otro lado, hay diferencias.

Couture, (3), define la Preclusión como "la pérdida, extinción o consumación de una facultad procesal".

La Preclusión no es pues una institución individualizada, particular, sino más bien una circunstancia atingente a la misma estructura del proceso.

\footnotetext{
(1) Castro, Máximo.- Curso de Procedimientos Civiles, dictado en la Facultad de Derecho de la Universidad Nacional de Buenos Aires, T. II., pág. 174.

(2) Chiovenda, Guiseppe.- Instituciones de Derecho Procesal Civil, T.I., pág. 464.

(3) Couture, Eduardo.- Fundamentos de Dereche Procesal Civil, pág. 96.
} 
La Preclusión puede tener su origen en tres situaciones diferentes:

a) Por no haberse observado el orden $u$ oportunidad establecido por la ley para la realización de un acto en el proceso;

(b) Por haberse ejercitado una facultad incompatible con el ejercicio de otra; $y$

(c) Por haberse ejercitado ya, válidamente, esa facultad.

La Preclusión en el proceso tiene como finalidad hacer posible el desarrollo ordenado del juicio. La Preclusión se funda, pues, no en la autoridad de la palabra del juez, que como hombre es falible, sino que se funda en una razón de utilidad práctica: la necesidad de que el proceso se pueda desenvolver ordenadamente señalóndose prara ello un límite a la facultad de discusión que tienen las partes normalmente en el proceso.

El carácter de inatacabilidad posterior que tiene la Cosa Juzgada se produce por la Preclusión de todas las cuestiones que surgieron o que hubiesen podido surgir en torno a la voluntad jurisdiccional con el fin de obtener el reconocímiento del bien negado o el desconocimiento del bien reclamado.

La Preclusión definitiva se produce cuando en el proceso se ha obtonido una sentencia que no está sometida a ninguna impugnación. Se tiene, entonces, una sentencia pasada en autoridad de Cosa Juzgada (Cosa Juzgada en sentido Formal). De modo que cuando contra la sentencia no cabe recurso impugnatorio se tiene la Cosa Juzgada en sentido Formal.

La Cosa Juzgada contiene en sí la Preclusión de cualquier discusión futura. Esta obligatoriedad de la decisión con relación a los juicios futuros es la Cosa Juzgada en sentido Material o Substancial y tiene como presupuesto la Cosa Juzgada Formal, o sea, la inatacabilidad o preclusión de la impugnación con respecto a esa decisión que ha pasado en Cosa Juzgada.

La Preclusión es pues, el medio de que se valo el proceso para establecer la autoridad de la Cosa Juzgada.

Pero hay también diferencias entre ambas instituciones.

La Preclusión limita sus efectos al proceso en el cual tiene lugar. En cambio, la Cosa Juzgada produce efectos vinculatorios para todo proceso futuro (Cosa Juzgada en sentido Material). La Preclusión, como se ha dicho, es el medio que hace posible la Cosa Juzgada, pero sólo la Cosa Juzgada, Y no la Preclusión, es la que vincula a los demás jueces.

La Cosa Juzgada es la eficacia propia de la sentencia que estima o desestima la demanda y se basa en la Preclusión, o sea, en la inatacabilidad de esa sentencia.

Fundamento de la Cosa Juzgada.

Con relación al fundamento o justificación de la Cosa Juzgada, existe entre los autores grandes diferencias de opinión que han dado lugar a la elaboración de una serie de teorías sobre el particular.

Me limitaré a mencionar las principales teorias que se han elaborado sobre este tema:

(a) Se dice con frecuencia que la Cosa Juzgada es una institución de Derecho Natural, impuesta por la esencia misma del Derecho, ya que sin ella sería ilusorio: reinaría la incertidumbre en las relaciones 
juridicas y se produciría el caos. Los Glosadores llevaron este principio al extremo, originóndose el dístico, que es citado por Couture: "La Cosa Juzgada hace lo blanco negro, origina y crea las cosas, transforma lo cuadrado en redondo; altera los lazos de sangre y cambia lo falso en verdadero".

Pero si bien es cierto que el Derecho necesita la certeza en forma imperativa, también lo es, que requiere de verdad, de modo que la justificación por la certeza no puede ser absoluta en ningún caso. Se tiene que considerar incluso, que la necesidad de certeza tiene que ceder frente a la necesidad de la verdad. Fl escrúpulo de verdad debe ser más fuerte que la necesidad de certeza y frente $a$ una nueva prueba o un hecho desconocido en el proceso anterior, se debería poder revisar el proceso hasta obtener la verdad.

La Cosa Juzgada parece, además, que no ha existido en el Derecho Antiguo y aún hoy funciona de manera diversa en las legislaciones, no existiendo, tampoco, un concepto uniforme de élla.

El examen sucesivo de la sentencia dictada, estaría más de acuerdo con la Justicia. No hay pues razón natural que justifique la Cosa Juzgada.

(b) La Tearía de la Ficción de la Verdad, elaborada por Savigny. La institución de la Cosa Juzgada no tiene nada de absoluto ni de necesario. Lo que justifica la Cosa Juzgada son razones de orden práctico y de utilidad que hacen que sea necesario poner término a la investigación judicial considerando la resolución del juez como ley irrevocable con relación al caso concreto.

Esta teoría considera que la institución de la Cosa Juzgada es la fuerza legal de la sentencia fundada en una ficción de la verdad, gracias a la cual la sentencia que pasa a tener la autoridad de Cosa Juzgada queda protegida contra toda futura impugnación. De acuerdo con esta teoría, la sentencia injusta pasaría a adquirir valor constitutivo de derechos.

No se puede sostener, además, que cuando en el proceso no se alcance la verdad se debe crear una verdad artificial, que tenga por objeto única y exclusivamente satisfacer al Derecho. No existe, como pensaba Savigny. una verdad "Quod iuris effectum".

(c) La Teoría de la Presunción Absoluta de Verdad, acogida por Pothier y consignada, también, en el Código de Napoleón.

De acuerdo con esta teoría el fundamento de la institución está en que se presume que la sentencia contiene la expresión de la verdad, de modo que no cabe una nueva discusión sobre este.punto. De ahí las máximas res" iudicato pro veritate habetur"; "res iudicati pro veritate accipitur".

La sentencia intachable crea una presunción juris et de jure de verdad. Pothier aceptó este carácter de verdad absoluta de la Cosa Juzgada y con este carácter se incorporó en el Código Civil Francés en el artículo, que dice: "La autoridad de la Cosa Juzgada no tiene lugar sino respecto de lo que ha sido objeto del fallo. Es necesario que la cosa demandada sea la misma, que la demanda se funde sobre la misma causa; que ella verse entre las mismas partes, y que hayan procedido en la misma calidad".

Esta teoría se diferencia de la enunciada en segundo término, en que, mientras que la anterior admite la posibilidad de que la sentencia pueda estar equivocada, y en este caso la justifica mediante una ficción. 
Ia segunda, parte de la hipótesis de que la sentencia no puede estar equivocada, no puede estar errada y transforma esta hipótesis en una presunción absoluta de verdad.

El Estado realiza su función jurisdiccional declarando el derecho en cada caso concreto y realiza esta función del mejor modo posible, rodećndola del máximo de garantías posibles, pero admitiendo siempre la posibilidad de error ya que la infalibilidad no es patrimonio de los hombres. Lo que sucede es que después de agotadas todas estas garantías, la hipótesis de que haya error no se admite desde el punto de vista del derecho, lo que no quiere decir, en modo alguno, que se transforme la Verdad Subjetiva, que es relativa, en Verdad Objetiva, que es absoluta. La presunción de que la sentencia contiene la Verdad Absoluta sólo puede descansar en el supuesto de que la Justicia sea infalible, que, evidentemente, no lo es.

(d) Pagenstecher elaboró la Teoría según la cual se podía equiparar los efectos jurídicos de la sentencia con los del contrato de declaración, o sea, el contrato por el cual dos o más personas establecen de un modo cierto $\mathrm{y}$ jurídico sus relaciones que pueden ser inciertas desde el punto de vista subjetivo.

Según Pagenstecher, hay semejanza entre la Cosa Juzgada y este contrato: así como la sentencia tiene firmeza aún cuando medie error, también las partes en este contrato se tienen que sujetar a lo estipulado en él aún cuando harya mediado error. Tanto la sentencia como el contrato de declaración establecen certeza jurídica entre dos partes con respecto de un derecho subjetivo.

Pero, como dice Rocco (4), no basta con afirmar que mediante un acto diferente de la sentencia se puede obtener la declaración de relaciones jurídicas controvertidas para afirmar la identidad de ese acto con la sentencia. Además, es necesario tener en cuenta que, la certeza jurídica que deriva del contrato de declaración es relativa e impugnable mientras que la que deriva de la sentencia, dictada por el Organo Jurisdiccional, es absoluta e incontrovertible.

(e) La generalidad de los autores consideran que el fundamento que justifica la autoridad de la Cosa Juzgada es de orden práctico $Y$ público ontes que jurídico. De esta opinión son Couture (5), Podetti (6) y Romero (7).

La Cosa Juzgada es necesaria, según esta doctrina, para que haya orden y estabilidad en las relaciones jurídicas: es necesario que las sentencias dictadas por el órgano competente del Estado tengan el carácter de definitivas.

Considera esta teoría que es necesario, además, tener en cuenta que el Poder Judicial ha sido creado precisamente para mantener la paz de la colectividad: de ahí que sus decisiones deban tener carácter de obligatorias cuando resuelven una controversia. El orden social exige que cuando un

(4) Rocco, Ugo.- Derecho Procesal Civil, pág. 314.

(5) Couture, Eduardo.- Fundamentos, pág. 247.

(6) Podetti. Ramiro.- Teoría y Técnica del Proceso Civil. págs. 178 y siguientes.

(7) Romero, Jorge Guillermo.- Estudios de Legislación Procesal, T. II.. pág. 124. 
asunto ha sido resuelto por el Poder Judicial con las debidas garantías señaladas en la ley (p.e. examen en más de una instancia; cumplimiento de todos los requisitos formales, etc.), el asunto no pueda volverse a discutir, ya que, de lo contrario, los pleitos no tendrían fin $y$ perturborían el orden haciendo imposible la convivencia social.

Podetii considera que la institución de la Cosa Juzgada obedece a un interés público y a un interés privado simultáneamente. Obedece $\alpha$ un interés privado, porque $\alpha$ las partes litigantes les interesa evidentemente que la resolución dictada en el juicio en el cual han intervenido quede inamovible. Obedece, asimismo, a un interés público que, a su vez, tiene dos aspectos: el principio de economía jurisdiccional, que se alcanza evitando que se discuta el mismo asunto dos veces y el principio de paz social. De estos dos fines tiene, en la Doctrina Moderna, mayor importancia el fin público, acentuándose esta primacía como consecuencia de la orientación publicista del proceso que domina en el derecho procesal moderno.

(f) Ugo Rocco ha elaborado su propia teoría sobre el fundamento o justificación de la Cosa Juzgada, consideróndola como la forma de extinción del Derecho de Acción. Según Rocco, la forma normal o natural de extinción de las obligaciones es el cumplimiento de la prestación que constituye el objeto de la obligación.

Hay relaciones jurídicas en las que el Estado es el sujeto pasivo do la obligación, como sucede con todas las relaciones obligatorias de Derecho Público, y que constituyen los derechos que el individuo tiene frente al Estado, en su calidad de ciudadano, para gozar de bienes, servicios o cosas que el Estado debe prestar a sus miembros.

Rocco considera que aún para esta categoría de derechos vale el principio cntes mencionado de que el cumplimiento de la prestación extingue la obligación. Entre estos derechos, Rocco coloca el derecho de acción ( $Y$ por tanto, también, el derecho de contradecir en juicio). La obligación que le corresponde al Estado es abstracta como lo es también el derecho de acción, mientras que el sujeto no se individualiza por medio de la demanda judicial o el recurso administrativo.

Según Rocco, el Estado cumple con su obligación jurisdiccional por medio de la sentencia final y de fondo que contiene la declaración de las relaciones jurídicas concretas deducidas en el juicio por medio de la acción. La sentencia final $y$ de fondo sólo tiene este carácter cuando se vuelve inatacable, inexpugnable, o sea, cuando ya se han ejercitado por los interesados todos los recursos de revisión que la ley les franquea o bien, cuando han vencido los términos para hacerlos valer.

En este momento queda cumplida la función jurisdiccional del Estado y hary en esta función dos aspectos segúm Rocco: de un lado, extingue el derecho de acción y de contradicción en juicio, y de otro lado, impide que el proceso se pueda renovar, por haberse extinguido la acción concedida a los interesados.

En esta función extintiva del proceso civil por obra de la sentencia de fondo inatacable es que Rocco coloca el fundamento jurídico y la justificación de la institución de la Cosa Juzgada.

Rocco resume su teoría de la siguiente manera: "En conclusión: así 
romo todo derecho subjetivo de obligación, público o privado, encuentra su fin natural en el cumplimiento de la prestación a que tiende, así también el derecho de acción debe necesariamente encontrar en el cumplimiento de la prestación de la actividad jurisdiccional su causa natural de extinción".

\section{Naturaleza de la Cosa Juzgada.}

El problema de determinar la naturaleza de la Cosa Juzgada no conslste en determinar si la Cosa Juzgada es una presunción de verdad o si es una ficción jurídica, etc., lo que sólo explicaría su justificación dentro del ordenamiento jurídico pero, en modo alơuno, su naturaleza. Las teorías sobre esta materia solo explican cómo funciona o por qué existe la Cosa Juzgada, pero no explican su naturaleza, es decir, qué es o en qué consiste la Cosa Juzqada.

Determinar la naturaleza de la Cosa Juzgada, para Couture, consiste en establecer si la Cosa Juzgada es el mismo derecho substancial que existía antes del proceso, transformando en indiscutible y susceptible de ser ejecutado coactivamente, 0 si, en cambio, es un derecho nuevo, independiente del anterior, nacido a consecuencia del proceso y de la sentencia.

Cuando se trata de determinar la esencia o naturaleza de la Cosa Juzgada se encuentran dos soluciones opuestas.

(a) Algunos sostienen que la sentencia y la Cosa Juzgada no son sino la determinación del derecho material o substantivo existente antes del proceso: se trata del mismo derecho material que existía antes del proceso y que ha sido convertido en indiscutible en la sentencia, impidiendo que se pueda renovar la discusión sobre ese tema en un nuevo proceso, pero sin que se haya alterado en nada el derecho anterior.

(b) Otros, en cambio, consideran que la cosa juzgada tiene un poder diferente al de mera declaración del derecho existente con anterioridad al proceso. La Cosa Juzgada no encuentra su eficacia en el derecho material preexistente a la sentencia sino en la sentencia misma una vez que ésta se convierte en indiscutible. La eficacia vinculatoria de la Cosa Juzgada no emana del derecho substancial anterior a la sentencia sino de élla misma.

La primera posición, parte de la base de que la sentencia no puede constituir, sino únicamente declarar, derechos. Según ésta posición el derecho material o substancial es preexistente al proceso, pero, sucede que cuando es desconocido o violado se necesita de una definición que ponga fin al estado de incertidumbre que se ha producido. Esta definición, para los partidarios de ésta posición, se hace mediante la sentencia, la que nada crea con relación al derecho anterior que queda exactamente igual a como existía con anterioridad a la sentencia, pero con certidumbre. Pero en realidad, la sentencia puede limitarse a declarar un derecho (caso de la sentencia declarativa), o bien, puede reparar el derecho lesionado (sentencia condenatoria), o, bien, puede crear estados jurídicos nuevos (caso de la sentencia constitutiva). Couture, considera que en todos estos casos la sentencia y su efecto natural, ésto es, la Cosa Juzgada, son una forma jurídica nueva que no existía antes de su expedición. 
Couture (8), refiriéndose a este problema de la naturaleza de la Cosa Juzgada, afirma que "la sentencia pasada en cosa juzgada puede ser una fiel interpretación del derecho substancial como puede no serlo. Este fenómeno es connatural a la Cosa Juzgada. Tan connatural como aquella otra cuestión... de que el derecho de acción lo ejercitan tanto los que tienen razón como los que carecén de ella".

De lo dicho se infiere que las sentencias injustas pasadas en autoridad de Cosa Juzgada, son tan sentencia como las demás, sin que éllo quiera decir que se les dé un valor más allá del que realmente tienen.

\section{Autoridad de la Cosa Juzgada.}

Se entiende por autoridad de la Cosa Juzgada su eficacia característica que consiste en "Ia fuerza o eficacia obligatoria inherente a la materia de la decisión judicial contenida en la sentencia" (9). Esta eficacia tiene por objeto proteger en un futuro proceso lo decidido por la sentencia.

La sentencia pasada en autoridad de Cosa Juzgada tiene una doble eficacia, adquiere dos atributos esenciales, que son: la coercibilidad, o sea, la posibilidad de ser ejecutada coactivamente en caso de resistencia de parte del obligado a cumplirla $y$, la inmutabilidad, o sea. la fuerza obligatoria de la Cosa Juzgada y que es lo que se denomina autoridad de la Cosa Juzgada. Es, pues, necesario diferenciar dos momentos: la declaración de la sentencia y la ejecución forzosa que son diferentes, pudiendo darse la declaración sin ejecución. Támbién la ejecución es independiente de la declaración definitiva y puede darse el caso de ejecución provisional de una sentencia que todavía sea susceptible de impugnación (caso del juicio de desahucio).

Se vé así la diferencia entro la Cosa Juzgada y lo juzgado. A la Cosa Juzgada, se reconoce como efecto, la fuerza obligatoria que impide la reproducción del proceso, y a lo juzgado, se reconoce como efecto la fuerza ejecutiva o sea la ejecución forzosa. El primer efecto está protegido por lo actio iudicati, que permite la ejecución de la sentencia pasada en autoridad de Cosa Juzgada.

Chiovenda (10), refiriéndose a la Autoridad de la Cosa Juzgada dice: "el bien juzgado se convierte en inatacable; la parte a la que el bien de la vida fué negado, no puede reclamarlo más; la parte a la que le fué reconocido, no sólo tiene derecho a conseguirlo prácticamente frente a la otra, sino que no puede sufrir de ésta ulteriores ataques a este derecho $y$ a éste goce".

Contra los reparos que formulan algunos autores respecto al carácter necesario de la cosa juzgada, Rocco (11) afirma que si se quitara éste carácter a la Cosa Juzgada, se alteraría la función jurisdiccional, ya que ésta quedaría reducida a una actividad puramente consultiva, cuando en

\footnotetext{
(8) Couture, Eduardo.- Ob. cit., pág. 252.

(9) Rocco, Ugo.- Ob. cit., pág. 272.

(10) Chiovenda, Guiseppe.- Instituciones, pág. 404.

(11) Rocco, Uga. - Ob. cit., pág. 274.
} 
realidad la Autoridad Judicial no debe absolver consultas, ni emitir simples opiniones, sino que debe emitir decisiones obligatorias. Ádemás, se causarián trastornos sociales si se suprimiera el carácter necesairo $\theta$ inconmovible de la Cosa Juzgada ya que la parte vencida pediría constantemente la revisión de la decisión.

En cuanto a los efectos procesales o derechos que derivan de la Cosa Juzgada, el Derecho Procesal Objetivo le atribuye los siguientes:

(a) La Autoridad de la Cosa Juzgada se presenta como una prohibición que excluye o limita el poder reconocido al individuo por el ordenamiento jurídico de acudir a los Organos Jurisdiccionales, o sea, el derecho de acción. Esta prohibición impone una inacción u omisión, ésto es una obligación de no ejercer nuevamente ese derecho con relación a esa situación jurídica concreta solicitando nuevamente a los Organos Jurisdiccionales la prestación de su actividad.

Dice Rocco (12): "Dicha Obligación negativa de no pretender un nuevo juicio y de respetar lo que ha sido juzgado, sometiéndose $\alpha$ ello, aparece como un límite impuesto por las normas de Derecho Procesal Objetivo al derecho abstracto de pretender o exigir de parte de los mismos órganos la declaración, mediante sentencia, de las relaciones jurídicas concretas, controvertidas o inciertas (derecho de acción)".

Como el derecho de acción entendido como facultad jurídica de solicitar o provocar la actividad jurisdiccional del Estado, compete, en el fondo, no sólo al actor que ha promovido la controversia sino támbién, en cierta forma, al demandado que se defiende en el juicio. la prohibición que impone la Cosa Juzgada rige también para el demandado que no puede, tampoco, promover un juicio provocando nuevamente la actividad jurisdíccional del Estado, sino que debe respetar y acatar lo que ha sido resuelto por los Organos Jurisdiccionales mediante una sentencia de fondo, final $\mathrm{y}$ que ha pasado a la categoría de Cosa Juzgada.

Las normas jurídicas se caracterizan por su bilateralidad: imponen una obligación $\alpha$ una persona y simultáneamente conceden $\alpha$ otro un derecho. Tratándose de la Cosa Juzgada, así como ésta impone a las partes una obligación, que es la de no poder provocar nuevamente la actividad de los Organos Jurisdiccionales, le concede simultóneamente un derecho al Estado, que es el de exigir a las partes que cumplan con esta obligación de no hacer $\mathrm{y}$ en consecuencia el derecho a negarse a juzgar nuevamente Io que ya ha sido resuelto una vez.

A este respecto dice Rocco (13): "La autoridad de la Cosa Juzgada se presenta, por un lado, como una obligación de las partes, actor $y$ demandado, de no reproducir una acción ya ejercitada y extinguida medianto el pronunciamiento de la sentencia pasada en autoridad de Cosa Juzgada: v, por el otro, como un derecho del Estado, por medio de sus Organos Jurisdiccionales, de no prestar la actividad jurisdiccional de conocimiento, una vez llenada, y por lo mismo extinguida, la obligación de jurisdicción civil de conocimiento".

(12) Rocco, Ugo.- Ob. cit., pág. 327.

(13) Rocco, Uga. - Ob. cit., pág. 328. 
(b) La cosa juzgada, además de imponer a las partes una obligación negativa y de conceder simultáneamente un derecho al Estado, produce como efecto una obligación para el Estado $y$ un derecho para las partes.

Los Organos Jurisdiccionales del Estado tienen así, no sólo la potestad - facultad, sino la obligación de no juzgar una vez dictada la sentencia definitiva en el juicio anterior entre las mismas partes. Recíprocamente, las partes no sólo tienen la obligación negativa antes mencionada, sino que tienen, además, el derecho de exigir que los Organos Jurisdiccionales no vuelvan a conocer del asunto que ya ha sido materia de una sentencia definitiva anterior y que ha pasado a la categoría de Cosa Juzgada.

De esta forma se vé, pues, que de la Cosa Juzgada surgen derechos y obligaciones subjetivas tanto para las partes como para el Estado.

Refiriéndose a las obligaciones que derivan de la cosa juzgada dice Rocco (14:) "La prohibición de hacer que se declare de nuevo una relación jurídica precedentemente declarada, mediante sentencia final de fondo pasada en autoridad de cosa juzgada, es una prohibición que gravita sobre el actor y sobre el demandado, independientemente del contenido de la sentencia pronunciada... ya sea que la sentencia haya sido favorable al actor, ya sea que lo haya sido al demandado, las normas procesales prohiben explícitamente $\alpha$ las partes pedir que se pronuncie, y a los Organos Jurisdiccionales pronunciar a petición de aquéllas, una nueva decisión sobre la controversia entablada y resuelta en un juicio".

El Códiqo de Procedimientos Civiles, en su artículo 1082, establece expresamente la fuerza imperativa de la sentencia pasada en autoridad de cosa juzgada.

\section{La Cosa jurgada Formal y la Cosa Juzgada Material.}

Para determinar en qué sentido la Cosa Juzgada obliga a las partes $\mathrm{y}$ a los terceros y hasta dónde ejerce su poder vinculatorio, es necesario distinquir la Cosa Juzgada Formal y la Material o Substancial. De modo que la institución de Cosa Juzgada puede ser considerada bajo este doble aspecto: uno que se relaciona con el descrrollo del proceso (Cosa Juzgado Formal) y otro que es un efecto exterior al proceso fallado (Cosa Juzgada Material o Substancial).

Couture (15) considera que la Cosa Juzgada Formal, consiste en la inimpugnabilidad de la decisión o sentencia por haberse agotado las revisiones que permite la ley, o, bien, por no haberse hecho uso de éllas por el interesado en la debida oportunidad. La Cosa Juzgada Formal deriva de la preclusión, que hace inimpugnable la sentencia, cumplidas determinadas formalidades prescritas en la ley. La Cosa Juzgada Formal, no obsta a que en un procedimiento posterior se pueda discutir $y$ modificar la sentencia porque en este caso sólo hay inimpugnabilidad pero no inmutabilidad de la decisión. La eficacia de la Cosa Juzgada Formal se produce, tan

(14) Rocco, Ugo.- Ob. cit., pág. 335.

(15) Couture. Eduardo.- Fundamentos, fágs. 257 y 258. 
sólo con relación al juicio concreto en que se ha dictado la sentencia o con relación al estado de cosas tenido en cuenta al pronunciar la decisión.

La Cosa Juzgada Formal es un efecto de la preclusión del derecho a provocar el cambio de la decisión, o sea, a impugnarla, y lo que significa, también, que ningún juez pueda estimar la situación jurídica de manera distinta de como fué considerada en la sentencia pasada en autoridad do Cosa Juzgada. De ahí la fórmula "res iudicata pro veritate habetur".

La Cosa Juzgada Material o Substancial se produce cuando a la condición de inimpugnabilidad, que constituye la Cosa Juzgada en sentido Formal, se suma la condición de inmutabilidad. De esta manera la Cosa Juzgada Material o Substancial supone al mismo tiempo que la inimpugnabilidad de lo resuelto, su indiscutibilidad. La Cosa Juzgada Formal viene a ser así, un presupuesto de la Cosa Juzgada Material en cuanto es su antecedente. La Cosa Juzgada Formal, como se ha visto, se produce por la preclusión: la sentencia se vuelve inimpugnable por no haberse hecho uso de los medios de impugnación señalados en la ley, o bien, por haberse agotado estos medios, y esta inimpugnabilidad es una condición o antecedente de la indiscutibilidad de la decisión, o sea, de la Cosa Juzgada en sentido Material o Substancial. La Cosa Juzgada Material o Substancial es, lo que los Romanos denominaban propiamente, la "res iudicata", es decir, la "res in iudicium deducta". Es la Cosa Juzgada en sentido Substancial la que sirve de fundamento a la excepción de cosa juzgada.

La condición de inmutabilidad que tiene la sentencia es según Carne_ lutti (16), una condición necesaria para lograr el fin del proceso, que es el de resolver situaciones de incertidumbre, lo que sin embargo no constituye un obstáculo, en opinión de ese autor, para que cuando la decisión sea a todas luces injusta y socialmente intolerable, las consideraciones de justicia deban prevalecer sobre la necesidad de certeza que busca el proceso. El fundamento de la inmutabilidad se encuentra pues, en la necesidad de que llegado el litigio a un cierto punto, las partes no puedan seguir discutiendo, ya que de otra manera éste no cesaría nunca.

Sin embargo, la inmutabilidad tiene el inconveniente de que, si bien satisface la necosidad de certezc, puede llegar a estar en pugna con la necesidad de justicia, ya que puede suceder que la decisión que quedo inmutable no sea justa. Carnelutti (17), es de opinión que a este problema sólo se le puede dar una solución transaccional $y$, por eso, se establece la revisión en variors instancias: se concede a las partes el derecho de impugnar la decisión hasta un cierto momento, pasado el cual a fin de satisfacer la necesidad de certeza, se cierra a las partes la posibilidad de impugnar la decisión, convirtiéndola en firme.

Se vé de esta manera, la conexión existente entre la Cosa Juzgada y la preclusión, a la que se ha hecho referencia más arriba, ya que la cosa Juzgada sólo se produce cuando ha operado la preclusión de todos los medios procesales de revisión de la sentencia.

(16) Carneluttl, Francisco.- Sistema de Derecho Procesal Civil, T.I., pág. 50.

(17) Carneluttit, Francisco.- Ob. cit., pág. 352. 
Resumiendo lo dicho: mientras que la Cosa Juzgada Formal se traduce en la inimpugnabilidad de la decisión, la Material o Substancial se traduce en la inmutabilidad e imperatividad de la decisión.

\section{Límites de la Cosa Juzgada.}

Es necesario diferenciar los limites objetivos y los límites subjetivos de la Cosa Juzgada.

\section{(a) Límites Subjetivos.}

Este problema consiste en determinar a qué persona alcanza la inmutabilidad y la eficacia de la Cosa Juzgada, o sea, el saber a qué sujetos de derecho no les es dado renovar el debate y cuáles, en cambio, sí pueden hacerlo. Determinadas las personas a las que alcanza la eficacia de la Cosa Juzgada, queda resuelto el problema de los límites subjetivos de Ia Cosa Juzgada.

El punto de partida básico para resolver este problema, es que la Cosa Juzgada sólo afecta, ya sea beneficiando o perjudicando, a aquellas personas que han litigado, que han sido parte en el proceso. La eficacia de la decisión o de la Cosa Juzgada sólo se refiere al litigio en el que ha sido producida $y$, por éso, sólo se extiende a las partes y sólo tiene eficacia de ley entre las partes. Dice Carnelutti (18): Si la autoridad de la cosa juzgada se refiere sólo a personas determinadas, ello deriva precisamente del hecho de que éstas son los sujetos del litigio; como la cosa juzgada se extiende exclusivamente al litigio deducido en el proceso, a élla están. sujetas únicamente las personas entre las que existe tal litigio". Para Carnelutti, el criterio para saber si una persona esta o no sujeta a la Cosa Juzgada, es el de determinar si su litigio ha sido deducido en el proceso en el cual se ha pronunciado la decisión.

Couture (19), señala como aplicación inmediata del principio de que la cosa juzgada sólo afecta a los que han sido partes en el juicio anterior, el que este principio rige, ya sea que el actor del primer juicio actúo como demandado en el segundo o vice-versa: el cambio de posición procesal de las partes no altera el principio.

Para que exista la Cosa Juzgada la ley exige la identidad de partes en ambos litigios, pero como dice Chiovenda (20), al igual que tratándose de los actos jurídicos entre las partes, la sentencia dictada existe y es válida no sólo con relación a las partes sino con respecto a todos, en cuanto tienen que reconocer como existente $y$ válido el estado de cosas entre los litigantes y que ha sido creado por la sentencia que ha pasado en Autoridad do Cosa Juzgada.

No puede, por tanto, establecerse como principio absoluto que la sentencia sólo produce efectos con respecto a las partes, ya que sus efectos

(18) Camelutti, Francisco.- Ob. cit.. pág. 335.

(19) Couture. Eduardo.- Ob. cit.. pág. 262.

(20) Chiovenda, Giuseppe.- Insttuciones, T. 1., pág. 442. 
alcanzan también a los terceros, pero la sentencia no puede beneficiar o perjudicar a otros que no sean los partes.

Todas las personas, aún las que no han sido partes en el litigio, están obligadas a reconocer la Cosa Juzgada entre las partes, pero no pueden ser perjudicadas por élla.

\section{(b) Límites objetivos.}

La Cosa Juzgada constituye un obstáculo o un límite frente a las posteriores decisiones de los Organos Jurisdiccionales.

Chiovenda (21), considera que la esencia de la Cosa Juzgada, desde el punto de vista objetivo, consiste en no permitir que el juez, en un proceso futuro, pueda disminuir ni menos desconocer el bien reconocido en un proceso anterior.

Esta limitación, que impone la Cosa Juzgada a los Organos Jurisdiccionales, puede ser total o parcial.

Es una limitación total, cuando la autoridad de la Cosa Juzgada Ilega a excluir o impedir la posibilidad de un nuevo juicio $\mathrm{y}$, por ende, de una nueva sentencia sobre ese mismo asunto; cuando el objeto de la sentencia anterior entre las partes, y el objeto de la nueva acción que se pretende ejercitar, coinciden, se identifican completamente.

Pero la Cosa Juzgada puede también imponer únicamente una limitación parcial o relativa a las decisiones de los Organos Jurisdiccionales, lo que sucede cuando el objeto de la sentencia que ha pasado en autoridad de Cosa Juzgada, no se identifica completamente con el objeto de la nueva acción que se pretende ejercitar sino que hay, únicamente, una coincidencia parcial entre ambas. En este caso, la exclusión u obstáculo que impone la Cosa Juzgada sólo se refiere a aquel aspecto en el cual existe coincidencia: sólo esta parte escapa al poder de decisión de los Organos Jurisdiccionales $y$ no es susceptible de un nuevo procedimiento.

De esta manera, también, se puede admitir, como dice Chiovenda (22) que "se puede poner nuevamente en discusión cualquier cuestión decidida, con tal de que el valor económico de la tutela jurídica ya conseguida no sea en modo alguno amenazado".

El problema de los límites objetivos de la Cosa Juzgada plantea a su vez dos problemas: determinar cuáles son las sentencias que causan o que determinan la Cosa Juzgada y, en segundo lugar, saber, cuál es la parte de la sentencia que causa la Cosa Juzgada o sea, si es sólo la parte resolu. tiva o si se forma también sobre los considerandos de la sentencia.

En cuanto a las sentencias que producen la Cosa Juzgada, sólo las sentencias definitivas o de fondo, es decir las sentencias que ponen fin al proceso, producen la Cosa Juzgada en sentido de Substancial o Material, ya que tienden a proteger los resultados del proceso fuera de él. Este principio lo reconoce nuestro Código de Procedimientos Civiles, en sus artículos 1080 al 1082, y en el artículo 317 al señalar como requisito para deducir

(21) Chiovenda, Giuseppe.- Instituciones, T. I., pág. 437.

(22) Chiovenda, Giuseppe.- Ensayos de Derceho Procesal Civil, vol. II. pág. 204. 
la excepción de cosa juzgada, que en el juicio anterior haya terminado por sentencia ejecutoria, o sea, definitiva.

Las sentencias dictadas sobre cuestiones de procedimiento no producen Cosa Juzgada en Sentido Substancial ya que sólo se refieren a relaciones que se consumen dentro del proceso mismo en el que son dictadas.

Estas sentencias interlocutorias producen Cosa Juzgada en sentido Formal mas no en Sentido Material o Substancial, ya que sólo quedan fuera de la posibilidad de impugnación de las partes. Producen, pues, Cosa Juzgada en Sentido Frmal precluyendo toda cuestión sobre el tema decidido, pero ésto tiene efecto solamente sobre el proceso en curso, mientras que la Cosa Juzgada Substancial o Material produce efectos más allá del proceso.

Couture (23), considera que todas aquellas sentencias que en Doctrina se denominan "provisionales", p.e., las dictadas en juicios de alimentos $y$, en general, todas aquellas que la ley permite contradecir, como sucede con las enumeradas en el artículo 1083 del Código de Procedimientos Civiles, sólo pueden explicarse fundóndose en la diferencia entre la Cosa Juzgada Formal y la Substancial; la primera permite que se reabra el debate, mientras que la segunda cierra el debate definitivamente. La diferencia fundamental entre ambas formas de la Cosa Juzgada radica en la inmutabilidad, o sea, en la posibilidad o imposibilidad de reanudar el debate, ya que ambas tienen la característica de la inimpugnabilidad.

El segundo problema que se plantea respecto de los límites objetivos de la Cosa Juzgada, consiste en determinar qué parte de la sentencia pasa en autoridad de Cosa Juzgada, es decir, si la Cosa Juzgada Substancial o Material se forma únicamente de la parte resolutiva o dispositiva de la sentencio o si se forma, también de los considerandos que han servido al juez para dictar resolución.

Savigny, que fué quien planteó el problema en primer término, consideraba la sentencia como un todo $\mathrm{y}$; que por lo tanto, la Cosa Juzgada comprendía íntegramente la sentencia.

Estas ideas de Savigny imperaron hasta fines del siglo pasado. La Doctrina y la Jurisprudencia moderna consideran que sólo la parte dispositiva de la sentencia es lo que constituye objeto de la resolución o decisión. Se considera que el Estado a través de sus Organos Jurisdiccionales tiene una voluntad o querer jurídico, pero no tiene un modo oficial de razonar. Las premisas o considerandos de la sentencia son sólo el proceso lógico que realiza el juez para elaborar la sentencia: La sentencia puede ser justa en la parte dispositiva $y$ errada en la parte considerativa, en los motivos; por lo que, si se considerase que la Cosa Juzgada se forma sobre toda la senteneia se produciría una colisión dentro de la Cosa Juzgada. De otro lado, las consideraciones o fundamentos de la sentencia son sólo un antecedente lógico del fallo y no pueden ser Cosa Juzgada pues ésta es una forma especial de autoridad que adquiere la sentencia como acto de voluntad.

Es necesario, sin embargo, tener en cuenta que los motivos o considerandos de la sentencia pueden, en ciertos casos, ser utilizados como ele mento interpretativo del fallo en el caso de que éste sea obscuro, ya que

(23) Couture; Eduardo,- Ob. cit., pág. 260. 
siendo antecedente lógico de la decisión debe reinar entre ambas partes correspondencia. Tienen desde este punto de vista interpretativo el mismo valor que los antecedentes en los demás actos jurídicos. Pero este valor interpretativo o ilustrativo que tienen los antecedentes no quiere decir, como opina Couture (24) que ellos pasen a constituir también cosa juzgada.

Requisitos para la procedencia de la excepción de Cosa Juzgada.

El medio de hacer valer, procesalmente, la eficacia de la Cosa Juzgada es la "exceptio rei iudicata" o excepción de Cosa Juzgada.

Ugo Rocco (25), la define como "la facultad que compete a aquéllos que han sido partes en un juicio anterior, de alegar y probar la existencia de la cosa juzgada, o sea la facultad de probar y alegar la existencia de aquella causa especial de extinción del derecho de acción y del derecho de jurisdicción, en que consiste la cosa juzgada".

Por medio de esta excepción no se pretende excluir precisamente una decisión contraria a la ya dictada, sino que se pretende excluir una nueva decisión, pura y simplemente, obligando al juez a reconocer la existencia $y$ validez de la decisión anteriormente pronunciada.

La excepción de Cosa Juzgada, como facultad que compete a las partes, $y$ en concreto al demandado en el nuevo juicio, es la facultad de pedir que los Organos Jurisdiccionales declaren la existencia de esa caura extintiva del derecho de acción y de jurisdicción del Estado.

Pese a que nuestro Código de Procedimientos Civiles menciona la excepción de Cosa Juzgada entre las dilatorias, propiamente es una excèpción perentoria pues, como dice Rocco (26), "en último análisis (la Cosa Juzgada) contiene la afirmación de la inexistencia de la acción, por haberse ejercitado y extinguido..."

Los requisitos de la Cosa Juzgada son los siguiente:

(a) Que la sentencia haya sido dictada por la autoridad legalmente encargada de administrar justicia; la ley;

(b) Que la sentencia contenga todos los requisitos establecidos par

(c) Que verse sobre cosa cierta y determinada en su parte dispositiva;

y

(d) Que la sentencia sea inimpugnable, bien sea porque no proceden contra ella más recursos, bien porque la parte interesada no se ha valido de los recursos que le tranqueaba la ley, en momento oportuno.

De acuerdo con el Código de Napoleón (art. 1351), para que la Cosa Juzgada se pueda hacer valer como excepción debe reunir las siguientes condiciones: "la cosa demandada debe ser la misma, la demanda debe ser fundada en la misma causa, la demanda debe ser entre las mismas par-

(24) Coulure, Eduardo.- Ob. cit., pág. 267.

(25) Rocco, Ugo.- Ob. cil.. pág: 336.

(26) Rocco, Ugo.- Ob. cit., plug. 339. 
tes". Esta regla llamada "de las tres identidades" ha sido reproducida en. casi todas las legislaciones con ligeras variantes de redacción, como sucede con nuestro Código de Procedimientos Civiles, que dispone en su. artículo 317:

"Para que las excepciones de transacción y cosa juzgada sean admisibles se requiere:

(a) Que las personas sean las mismás que transigieron o siguieron el juicio, sea por derecho propio o transmitido legalmente;

(b) Que la acción y la cosa sean idénticas;

(c) Que el juicio haya terminado por sentencia ejecutoriada, si se trata de la excepción de Cosa Juzgada.

El primer requisito que señala el Código para Ia procedencia de esta excepción es que las personas que intervengan en los dos juicios sean. las mismas, bien sea por derecho propio o transmitido legalmente.

La sentencia sólo tiene autoridad de Cosa Juzgada entre las partes que hayan seguido el litigio. La identidad de personas a que alude la ley, se tiene que entender en el sentido de que las personas sean juridicamente las mismas y no en el sentido de una identidad física. La ley se refiere, pues, a la calidad jurídica de las personas que han intervenido en el litigio.

Una misma persona física puede tener diferentes personalidades jurídicas y personas físicas diferentes pueden tener una misma personalidad jurídica, v.g., en el primer caso, $A$ es socio de una compañía $y$ es, al mismo tiempo, curador de $B$; el segundo caso sería el de un heredero y su causante que tienen, jurídicamente, la misma personalidad.

El principio de representación para justificar la fuerza vinculatoria de la Cosa Juzgada rige en todos aquellos casos en que la ley otorga a una persona el derecho o legitimación procesal para actuar en juicio en nombre y representación de otros, v.g., el padre por el hijo menor; el tutor por el pupilo, etc. La cosa juzgada dada contra el representante en todos los casos alcanza al representado.

Prescindiendo de los casos de representación, también se considera que hay identidad de partes tratóndose de la persona que adquirió un bien por herencia, donación, compra o cualquier otro título legítimo, sustituyendo al poseedor anterior en todos sus derechos $\mathrm{y}$ acciones $\mathrm{y}$ que ejerce sobre el bien los mismos derechos que tenía el poseedor anterior. En este caso, pese a que las personas sean físicamente diferentes, el nuevo poseedor no podría alegar esta circunstancia para sustraerse de los efectos de la cosa juzgada, dictada contra su predecesor.

La cosa juzgada, en cambio, no alcanza a quien no ha sido repre. centado ni es sucesor a título universal o particular, o acreedor o comprador - cesionario.

Por ello, la ley al referirse a esta identidad alude no sólo a las personas que siguieron el juicio por derecho propio sino también a aquellos cuyo derecho les fué transmitido legalmente, sin ninguna restricción en cuanto al título por el cual el derecho fué transmitido. En todos estos casos, se considera que hay identidad de partes $y$, por tanto, el demandado podría hacer valer la excepción de Cosa Juzgada acogiéndose al fallo que favo. reció a su antecesor. 
(b) El segundo requisito, que señala el Código, para que se pueda deducir la excepción de Cosa Juzgada es que las acciones sean idénticas. Ia fórmula del Código, no es exacta y dá lugar a dificultades. Fn la generalidad de las legislaciones extranjeras, no se utiliza la fórmula identidad de acciones sino la de "demanda fundada en la misma causa", que es una fórmula mucho más conveniente y clara, ya que no existe identidad de acciones cuando éstas se fundan en distinta causa.

Cuando la causa con que se ejercita la acción es diferente no hay identidad de acción, ya que ésta sólo existe cuando las acciones se fundan en la misma causa y persiguen el mismo fin, siendo por ello substanciadas en Ia misma forma.

Es por ello que la expresión utilizada por el Código de Procedimientos Civiles en su artículo 317, ha debido ser substituída por la de "demandas fundadas en la misma causa", y que es, sin lugar a dudas, el sentido que le ha querido dar el Código al término acción, como se desprende del crtículo 1082.

(c) El tercer requisito señalado en el artículo 317, para que se pueda deducir la excepción de Cosa Juzgada, es la identidad en cuanto a los objetos de la demanda, y la razón de ello es que, como se afirma en Doctrina, "Ia autoridad de la Cosa Juzgada no se extiende más allá del objeto sobre el cual se ha decidido explícita o implícitamente en la sentencia" (27).

Es necesario tener presente que nuestro Código de Procedimientos Civiles, de acuerdo con el Código Civil de 1852, utiliza la palabra "cosa" en su sentido más amplio, significando con ella toda clase de bienes tanto corporales como incorporales.

No es necesario que la identidad de objetos sea integral o absoluta: los aumentos o disminuciones que la cosa materia del primer litigio haya recibido o sufrido no constituyen un obstáculo para que se considere que existe identidad y que hay, por tanto, Cosa Juzgada. En el mismo sentido se pronuncia Romero (28) al afirmar que "este concepto legal sobre identidad de cosa, sin duda no puede ser absoluto, porque cuando no se trate de un objeto material que pueda concreta y determinadamente señalarse, como un mueble o una finca, sino cuando se trate de objetos que pueden ser substituídos por otros equivalentes, esa equivalencia y la igualdad del número serón los elementos constitutivos de la citada identidad legal".

Las partes integrantes de una cosa o los derechos particulares comprendidos en un derecho más general del que no es posible separarlos, forman una misma cosa con este objeto o derecho. Los trutos civiles o naturales $Y$, en general, los productos de una cosa se consideran formando un solo y mismo objeto con esa cosa.

Tratándose de sentencias dictadas por un tribunal extranjero se plantea el problema de saber si pueden servir de fundamento para invocar la

(27 Aubry et Rau.- Droit Civil Francais. - Tomo VII, pág. 378.

(28) Romero, Jorge Guillermo.- Ob. cit., pág. 144. 
excepción de Cosa Juzgada on caso de que se trate de iniciar un nuevo proceso ante un tribunal peruano.

Nuestro Código de Procedimientos Civiles en el Título XXXX, de la Sección. II, establece las reglas para dar fuerza ejecutiva $\alpha$ las sentencias y, en general, a las resoluciones dictadas en países extranjeros.

De acuerdo con el Código, cuando haya Tratado celebrado con el país donde se dictó la sentencia, ésta tiene el valor que se le señala en ese Tratado. Cuando no haya Tratado, nuestro Código sigue la regla de la reciprocidad legislativa: se reconoce en el Perú a la sentencia dictada on el extranjero el mismo valor que en ese país se reconoce a las sentencias peruanas. Cuando el país extranjero no reconozca valor a la sentencia dictada por un tribunal peruano o se le someta a revisión en el fondo, tampoco tendrón valor en el Perú las sentencias dictadas en ese país extranjero.

En ningún caso se puede reconocer valor, en el Perú, a las sentencias dictadas en el extranjero y que se refieran a situaciones respecto de las cuales los jueces peruanos tienen competencia excluyente o exclusiva (Arts. 1158 y 1159 del Código de Procedimientos Civiles).

\section{Efoctos de la cosa lurgada sobre el derecho substancial.}

Existen actos jurídicos procesales que tienen como característica el producir un doble efecto: uno de índole procesal, $y$, otro de derecho substantivo. Tal es el caso, p.e., del acto procesal con el cual se inicia el proceso, es decir la demanda, que junto con el efecto procesal de dar comienzo al proceso poniendo en movimiento a los Organos Jurisdiccionales del Estado, produce efectos sobre las relaciones jurídicas substantivas, v.g., en materia de prescripción (Código Civil, art. 1183), en materia de mejoras (Código Civil, art 835), etc. Se reconoce, pues, a ciertos actos procesales, además de su efecto directamente procesal, efectos sobre las relaciones jurídicas substantivas.

Tratándose de la Cosa Juzgada, en particular, ésta además de producir efectos en el campo procesal los produce también sobre las relaciones jurídicas substantivas.

La Cosa Juzgada, como ya se dijo, produce como efecto la obligación de las partes de someterse a la sentencia que ha sido dictada por los Organos Jurisdiccionales $y$ que ha pasado a la categoria de Cosa Juzgada $y$ produce, asimismo, la obligación de parte de los Organos Jurisdiccionales de abstenerse de conocer nuevamente de aquellos asuntos que han pasado a la categoría de Cosa Juzgada.

De aquí deriva el primer efecto de la Cosa Juzgada sobre las relaciones jurídicas substantivas: no pudiendo las partes pretender una nueva declaración sobre las relaciones jurídicas juzgadas, ni pudiendo los Organos Jurisdiccionales dictarla, las relaciones jurídicas de derecho substantivo que han constituido el objeto de ésa declaración quedan definitivamente fijadas, en cuanto no pueden ser objeto de una nueva declaración. Esta fijeza y estabilidad de las relaciones jurídicar substantivas es un efecto normal y característico de la Cosa Juzgada. 
La estabilidad y tijeza de las relaciones jurídicas substantivas no es un efecto directo o inmediato de la Cosa Juzgada, sino que es un efecto indirecto o reflejo.

En efecto: entre la Cosa Juzgada y su efecto procesal, o sea, la autoridad de la Cosa Juzgada, existe una relación de causalidad jurídica, es decir, una relación directa de causa a efecto. En cambio, el efecto de derecho substancial, o sea, la estabilidad $y$ firmeza de las relaciones jurídicas declaradas, es una consecuencia del efecto de derecho procesal, o sea, es un efecto de la autoridad de la Cosa Juzgada. De esta manera, la Cosa Juzgada aparece frente a los efectos procesales como causa directa y trente $\alpha$ los efectos de derecho substantivo aparece como causa remota o indirecta.

No se debe, por tanto, considerar a la Cosa Juzgada como causa directa de los efectos procesales y substantivos simultánecrmente, pues éstos son consecuencia o efectos de aquéllos. 